\title{
Novelty Governance Mechanisms to Govern Cameroon to Sustainable Peace, Prosperity and Thriving Growth
}

\author{
Maxwell N. Achu (Diplomat)
}

(Peace Advocate, Conflict Transformation Researcher, Academia, MA. International Relations), Cameroon

\begin{abstract}
THE AUTHOR'S OBJECTIVES
Barbara Walter reportedly said 'old wars restarted by the same rebels after a period of peace'1 a trend apparently common in the continent ${ }^{2}$. According to Walter's study 90 per cent of all civil wars by the year 2000, were repeated civil wars. What is the underlying defect? Bad governance is at the core to such relapse in armed conflicts. By this, I wish to stress that, orthodox peace making procedure would not apply in the anglophone context; as many of such complex armed conflicts was not solved by such peace making therapies; rather, a re-modeling of governance strategies by the central government is the requirement through holistic peacebuilding programs.
\end{abstract}

As Walter further stressed, civil wars are more likely to repeat themselves in countries where government elites are unaccountable to the public, where the public is hindered from absolute participation in the political life of the state, and where information is not transparent ${ }^{3}$. It is not democracy or poverty per se', she concluded, 'but very specific accountability mechanism that make countries more or less likely to experience repeat war'. This is core to governance, as I have illustrated below the link between the level of peacefulness a country enjoys and its governance mechanisms. This brings my earnest objective to the fore, which is to re-stimulate the seemingly bleak governance environment in Cameroon and make appropriate interventions through suggestions for the attention of the government in particular and the Cameroonian people in general.

For this cause, I have elaborated on the reasons for Cameroon's fragility and proposed resolutions and timely interventions to contribute in mitigating the rising risk that comes with fragility - violence. Given that the nation is already plagued with high levels of violence and the recent post-election violent environment, coupled with political instability, I have proposed some innovations along the lines of governance devices to prevent further escalation of violence and other forms of armed conflict.

Whether governance mechanism succeed lies in the impartial and equitable commitment of policymakers in the implementation of pro-equity social policies, and solving the commitment problem is crucial to bind political power-

\footnotetext{
1 Walter, Barbara F. 2015. "Why Bad Governance Leads to Repeat Civil War." Journal of Conflict Resolution 59 (7): 1242-72

2 Williams, Paul. 2017. "Continuity and Change in War and Conflict in Africa." Center for Security Studies. Vol. 6, Number 4 of PRISM by the NDU Center for Complex Operations on 16 May 2017.

3 Walter, "Why Bad Governance," 1243
}

players and policymakers to commit and deliver upon earmarked social and economic pledges.

In all, my utmost desire is to see the improvement of development variables growing on the hinges of high quality governance, and set Cameroon on the stage to meet up global developmental goals, as the world becomes better for successful living. Ultimately, this would make Cameroon become more secure, peaceful, reduce violence containment expenditure as well as spur growth and macroeconomic development.

\section{INTRODUCTION}

To understand comprehensively fragility, resilience, peace and economic growth, the need to measure and quantify the low levels of quality governance is of utmost importance. The importance of the development variable of governance was demonstrated on January 1, 2016, when the United Nations (UN) member states' approved global goals came into force. These development goals provide a predominant and integrated framework for global action on a vast range of critical issues for the next 15 years. Amongst these goals, Goal $16^{4}$ - Peace, Justice and Strong Institutions, is the most ambitious goal of the Sustainable Development Goals (SDGs) in many respects but governance is the focus of this concept paper. Goal 16 recognizes governance, inequalities and institutions as important variables for sustainable development. It however consist of 12 targets, measuring governance, justice drivers of violence et al., and faces unique practical challenges in its measurement and implementation.

Stressing on the importance of governance as the predominant development variable, according to the SDG 16, the author further qualifies that, underlying the roadblocks to sustainable development is the element of bad governance. According to the author, the goals for peace, growth and equity all hinges on good governance for effective policy implementation and productivity. This ultimately means if appropriate governance mechanisms are in place alongside implementable policies, then, all other human development setbacks will find bearings of success and accomplishment. Therefore, governance becomes the epicenter on which all other developmental factors owe their successes. Indeed, to overcome all threats to human security depends strongly on overcoming the challenges of governance. Illustratively, researchers estimates that when governance is improved by one standard deviation, income

\footnotetext{
4 Promote peaceful and inclusive societies for sustainable development, provide access to justice for all and build effective, accountable and inclusive institutions at all levels
} 
rise about three-fold in the long run, and infant mortality declines by two-thirds.

Governance dividends should not be overemphasized, as it is usually high. The truism is that, the onus of sustainable growth, prosperity and development rest on the quality of governance operating in any given country. Therefore, bad governance or the state of governance deficit is usually highly associated with anti-development vices like violence, poverty, economic stagnation, fragility and low levels of resilience and adaptability.

Measuring and defining the quality of governance can be an uphill and daunting task, and debated across research circles. Several criticisms have emerged to counter the results and measuring indicators of the World Governance Indicators $-\mathrm{WGI}^{5}$. Some of these criticisms goes to question the usefulness of the WGI for making comparisons of governance overtime and across countries ${ }^{6}$, as some describes these indicators as 'elaborate untested hypothesis'7, even as far as questioning the causality between governance and growth. In spite of all these criticisms the WGI are currently used effectively to measure the state of governance and its quality in countries, as recommendations proceeding from such measurements has recorded and still recording unbelievable strides for other developing/developed economies across the world. As Lord Kelvin famously remarked, if you cannot measure it, you cannot improve it. By supplying the tools to measure governance and monitor changes in its quality, the World Bank $^{8}$ and other related research enterprises have helped reshape the framework within which governance reforms are implemented, not only giving readers a better and deeper understanding of countries strengths and weaknesses, but also by offering insights and evidence of how reforms can generate development dividends. More interesting, donor agencies, too, have concluded that development assistance is more effective in countries with good institutional quality (good governance). Increasingly, international financial institutions and some bilateral donor agencies, subscribing to evidence-based policy and decisionmaking, explicitly tie aid transfers to governance outcomes, as they rely on a variety of WGI to make informed-decisions. To this effect, the author confirms that, the WGI does not fail to measure what they claim to measure.

\footnotetext{
5 The WGI project combines data from a large number of underlying sources to construct six aggregate governance indicators: Voice and Accountability - VA, Government Effectiveness - GE, Regulatory Quality - RQ, Political Stability and Absence of Violence/Terrorism - PV, Rule of Law - RL, and Control of Corruption - CC. Hence, these six aggregate indicators capture the political, economic and institutional dimensions of governance.

${ }^{6}$ Amdt, Christiane and Charles Oman (2006). "Uses and Abuses of Governance Indicators". OECD Development Center Study

7 Thomas, Melissa (2006). "What Do The Worldwide Governance Indicators Measure?" Manuscript, Johns Hopkins University

8 World Bank Policy Research Working Paper 4149. March 2007. Daniel Kaufmann, 1818 H Street. NW, Washington, DC 20433,dkaufmann@worldbank.org: Massimo Mastruzzi mmastruzzi@worldbank.org and Aart Kraay akraay@worldban.org
}

Notwithstanding, this concept paper does not aim to measure the quality of governance in Cameroon within the context of all six WGIs, rather the paper seeks to outline in generic terms the poor state of governance resulting from high levels of developmental setbacks inherent in Cameroon, including violence, poverty, decried marginalization, heightened segmentation, and high levels of corruption et al. The author is more interested in demonstrating that, the effects of governance deficits engenders fragility, weakens resilience and lowers institutional adaptability in response to both endogenous and exogenous shocks (SECTION 1). The predominant consequence of fragility is insecurity, ultimately implying that, the quality of governance is reflective of the quality of security a country may experience. Therefore, high levels of governance deficit is an enabler for insecurity, as well as violent escalations (SECTION 2). However, the forward-looking re-modelling and revising of governance strategies to improve developmental outcome is even more vital than sections 1 and 2's analysis. How can the government of Cameroon (henceforth GoC) enhance innovative governance practices within the context of accountability, transparency, public service delivery et al., to improve the wellbeing of Cameroonians, as well as increase the probability for growth and prosperity?. Most importantly, effective and equitable institutions are core in realizing innovative governance principles highlighted herein. This means without effective institutional arrangements - which are essential for efficient management of the complex policy sectors like fiscal policy, poverty reduction policy, infrastructural policy, and employment policy, all these governance proposals will succeed exclusively on paper. There is therefore an urgent requirement to broaden the current governance environment (effective decentralized governance for example), with effective and equitable institutions to serve as a platform for sustainable peace, growth and achievements. Critical attention therefore, should be given to the performance of these institutions, within the framework of the functions they undertake and not only the forms have they taken (SECTION 3).

This concept paper is geared towards encouraging the exchange of ideas about development issues within Cameroon, as it amounts to the author's contribution among other empirical research aimed at measuring the quality of governance in Cameroon, monitor Cameroon's progress in achieving global development goals, understand the causes and effects of good and bad governance for sustainable development. It is Maxwell's earnest desire, with several other researchers, to see Cameroon scale new heights in governance quality and reap the dividends that comes with such structural political transformation. However, it will be an over exaggeration to think this concept paper has all solutions regarding the high levels of governance deficits inherent in the intended context (Cameroon). Nonetheless, its contribution certainly should induce the government, civil society organizations, corporate and multilateral organizations, community rulers, banking, finance and business tycoons, students as well as academia to read the literature and practice the principles, as this would greatly influence awareness and redress thought patterns in line with governance mechanisms. Eventually, an effective application of these proposed governance guidelines would witness a smart creation of a conducive governing space in a bid to re-stimulate the entire governance environment in Cameroon. 


\section{SECTION ONE: HIGH LEVELS OF GOVERNANCE DEFICIT AND THE LACK OF A CULTURE OF GOOD GOVERNANCE HAS PROMPTED, ENGENDERED AND INTENSIFIED FRAGILITY IN CAMEROON}

It is a generally an agreed perception, even within the circles of critical researchers, that fragility is an effect of bad governance, even though the effect of fragility can be low governance quality as well. however, the former perception is illustrative of the fact that, when countries fail to meet their development targets and other related socioeconomic objectives, the underlying reason, even though not always accepted, is anchored in bad governance. However, this perception - though scientifically proven can be argued at several fronts. Core reasons of bad governance can be exogenous (price shocks and market volatilities, as examples), in which case the circumstances are well beyond the capacity or control of policymakers and leaders. Conversely, the predominant setbacks to development owe their failures to endogenous shocks, like flawed financial expenditure and incoherent fiscal policy as concerning public investment. The effect of such inconsistency with financial regulations is at the heart of underdevelopment, which comes with other multiplier threats like high levels of corruption, low levels of employment, widespread of tropical diseases, lack of health services, poor infrastructural developments, as well as high risk of violence eruption. It is highly established that bad governance is at the heart of low levels of development and violent eruption.

\section{Governance Deficit in Cameroon has caused Fragility}

The exclusion of key segment (in this case - the Englishspeaking regions, according to some analyst) in the society from core political processes lies at the heart of the grievances called the 'anglophone uprising'. For all the readers may know, this crisis started as a peaceful demonstration of English-speaking lawyers, which has turned bloody. What can account for such devastation? Many other variables can explain the deleterious state of affairs, but strongly, unstructured governance practices is fundamentally the main reason. Because the previous governance mechanisms left the crisis unaddressed, more violence was incited and hence armed groups emerged. Whether or not the crisis an underlying political undertone is another argument altogether. However, if the crisis has gone soar, then, governance institutional arrangements to enhance conflict resolution and prevention did not do a good job and should be revisited. According to some analysts, this scenario of governance that caused the outbreak of the crisis is called exclusionary governance, as it is the predominant cause of fragility in Cameroon, even as it presents aggravated challenges for development agencies.

Nonetheless, transitioning Cameroon from the high state of fragility to peace or resilience and adaptability is non-linear in nature, as this would demand consistent implementation and evaluation with close follow-up of holistic peacebuilding programs, as suggested in the author's reflections entitled 'conclusions of the anglophone crisis risk assessments, and the predictability of the crisis' intensity. The clock is ticking...'

This implies that building governance quality in such a violent-affected scenario is always a mammoth task and requires high levels of tactfulness in both peacebuilding and governance. This is simply to call to the attention of policymakers that governance deficits should never be met with 'quick fixes' or 'early wins' measures, including hasty implementation of peace agreements, as this has lost value and insights to consolidate peace within conflict resolution, transformation and prevention circles ${ }^{9}$. This was just to reiterate that, the current violent crisis rampaging the country, dubbed the 'anglophone crisis' is a significant determinant on the governance strategies within the country. To support therefore the government and other stakeholders' in settling this bloody dispute, applying the concept of 'exit strategies' with the ultimate goal of peace consolidation will not work, at least not for the long-term ${ }^{10}$.

The current state of the crisis has exposed, if not for the better, the weak structures of governance inherent in Cameroon. Moreover, if care is not taken, this prototype form of fragility can be so erratic, which brings with it other recurring and cascading crises that will erode Cameroon's national and local capacities to respond effectively. In such situations, like the present one in which Cameroon finds itself, the national government and other related development agencies should support governance strategies in parallel settings with the exigencies of peacebuilding and statebuilding extensively.

\section{Lack of a Culture of Governance}

As earlier stated, the author's objective is not geared towards apportioning blames rather to propose governance mechanisms to spur growth, encourage the debate on development issues, and enhance productivity. Therefore, it is not whether there is a governance culture or not, but how can the government improve the effectiveness of its function to ensure a sustainable culture of governance like in Botswana or Ghana.

That said, a culture of good governance entails an in-depth construction, wherein, the societal changes in Cameroon is reflected in the attitudes of Cameroonians as they are oriented toward peaceful development, productivity, growth, adequate and ultra-modern public service provisions and public good over sectarian interest. Prior to highlighting the author's proposals to build a culture of governance, it is of utmost importance to mention that governance culture setting fundamentally must be driven by political will (government will) and national ownership - this emphasizes the role of political leadership. This brings to mind the 2006 Survey on Monitoring the Paris Declaration, which ranked Rwanda 'ownership' meaning the 'ability of a country to exercise effective leadership over its development policies and strategies', as outstanding. The GoC has a lot more to learn from precedents from countries with high levels of governance culture like Mauritius. Below are proposals for the GoC to build a good governance culture.

Firstly, the GoC should build and update the capacities of implementators, and institutions for the designing and implementation of peace-sensitive policies. The whole process of designing these policies in strict consultation with professionals in peace studies is what the author calls 'policy mixing'. Mindful of the fact that human security threats are

${ }^{9}$ See E. Newman, R. Paris, and O.P. Richmond, (eds.), New Perspectives on Liberal Peacebuilding. (Tokyo, United Nations University Press, 2010)

${ }^{10} \mathrm{~N}$. Armstrong and J. Chura-Beaver, Harnessing PostConflict Transitions: A conceptual Primer. (PKSOI Paper, 2010) See Also, DPKO, A New Partnership Agenda: Charting a New Horizon for UN Peacekeeping. (New York: DPKO, 2009) 
becoming vaguer than before, it is important to build capacities of implementators to correspond the contrary challenges (violence) facing humanity at large and Cameroonians in particular. Selecting these implementators should go through a competitive process, so that qualified and committed executioners will be tasked with governance complementaries, especially as they would be compelled to deliver based on their competencies.

Secondly, the GoC should sequence and integrate activities and increase the level of peacebuilding program and interventions to mediate forecasted risk of violence escalation or intensification, as is the case of the anglophone crisis. The main feature of this intervention must be the holistic approach, designed in a system-thinking fashion such that successes in one procedure or part should ultimately have a spill over positive effect on the other.

Thirdly, the GoC should be able to forge effective partnerships, as the political institutions that be, must have learnt that nothing could be made in isolation, given the globalized world in which societies are engulfed. More so, just as the present crisis is sophisticated, the GoC need solutions to even-up, to mitigate and solve these crises, including the current armed conflict rampaging the peace of the nation. Therefore, partnerships are a priority for the nation. Some effective partnerships could be strongly tied between national institutions and international community agencies, for example the public donor agencies and NGOs, or between institutions of public and private sectors including the civil society and the common citizen at national and local levels. External assistance in the form of partnership can help restore the quality of governance especially in Cameroon driven by violence and armed conflict, as well as enable the devastated war-torn cities to meet the daunting challenges of reconstruction ${ }^{11}$. The Cameroonian people should not have imperialistic feelings to drive them to think external partnership may connote external control of internal governance systems and policies. No. Cameroon must have ownership of the entire governance process, as was the case of Rwanda, as this is critical for governments - including Cameroon, to acquire the capacity of managing external relations and forging alliances with a vast range of stakeholders. Ultimately, such alliances between domestic governments and external partners must operate within coordinated peace-sensitive approach.

Complying with these governance mechanisms to build a culture of governance will not only enhance growth and development but will as well plunge a Cameroon into a virtuous circle of peace, and prosperity. Such virtuous cycle will create a strong business environment, better functioning government and higher social cohesion. This will increase Cameroon's rank in the Ease of Doing Business Index, and attract in foreign direct investments as well as encourage domestic trade and transactions. This will ensure that Cameroon reaches higher levels of wellbeing for Cameroonians, having them become more productive and eventually wealthier. The upshot of such policy constructivism will see the $\mathrm{GoC}$ spending less on violence containment expenditure, thereby releasing more resources

\footnotetext{
11 This fact is well substantiated in: The Challenges of Restoring Governance in Crisis and Post-Conflict Countries, Rondinelli and Cheema, 2007
}

to be free for investment in productive ventures like agriculture and other agro-related processes. The spillover effect of such environment will improve peace and other measures of progress and will lead to less violence, as the Cameroonian society will be prone to non-violent means of conflict resolution, as it will further create a conducive atmosphere for business and growth.

Conversely, less compliance may engender high levels of governance deficit, as disgruntled Cameroonians may incite violence of resistance and deteriorate the already low state of peace in the country. Such environments increase the potentials for grievances, as other factors like lower levels of equity, justice, fairness and trust endangers peace. Institutional fragmentation will increase the risk of more violence, as resilience weakens further and deteriorates national peacefulness. When violence breaks, the cost associated with such disruptions will increase, as resources meant for productive areas would be spent on managing such violence.

\section{SECTION TWO: QUALITY GOVERNANCE IS A PRECONDITION FOR QUALITY SECURTY IN CAMEROON}

This concept paper does not mean to undermine the security threats facing the total extinction of the human race like climate change, as it refers to security within the context of ending wars, civil conflicts, armed conflicts, internationalized internal armed conflicts, inter-state armed conflicts, genderbased violence, genocide as well as other forms of violent conflicts. The conceptual meaning of security is linked closely and in accordance with the African Union's (AU) AGENDA 2063, wherein the non-binding instrument boldly highlights the phrase 'silencing the guns by 2020', to mean ending all wars and violent-related conflicts within the subregion and in Cameroon in particular.

To contextualize, security of the Cameroon people will invariably mean- freedom from violence (coercion) and/or the threat of violence. Contrariwise, insecurity will connote the prevalence of violence, like the anglophone crisis, or even the threat of further escalations thereof. The author, therefore measures security in Cameroon as the reduction in the incidence of direct violence (the ongoing crisis), which he defines briefly as harming people with intention. Stressing on the Cameroonian people will mean this concept paper will be dealing with insecurity towards Cameroonians, as a people, thereby contrasting it to transnational human security threats ranging from climate change, to food security and water scarcity, to infectious diseases, to wild life poaching - just to name a few. The meaning of security here is however broader than the regular concept of citizen security, which ranges from interpersonal crimes and homicides.

This concept paper addresses violent conflict, as a driver for high levels of bad governance, meaning conflicts is a result of a breakdown in governance quality. Nonetheless, the author is more concerned with solution-oriented data analysis, as he pays more attention to the role of smart and innovative governance mechanisms to improve security by reducing, or ending violent conflicts. In other words, the preceding section demonstrates that qualitative governance schemes are a predominant determinant in qualitative security, as these schemes will serve as enablers to prevent conflicts or for the very least, stopping them from becoming violent. Readers should be reminded that, the author pays no 
attention to the concept of legitimate use of violence, as this is at variance with the objective of this concept paper. The author is more interested in governance mechanism that can avoid violence in the first place, and if violence inevitably erupts, what institutional forms of governance arrangements should be implemented to mitigate the effects that comes with violence? It is not about analysis but more about solutions.

\section{$>$ Cameroon's Fragility is illustrative of high levels of violence, as it ultimately affects core government functions and Governance Processes}

Straight away, the current crisis in the South and North West regions, coupled with high levels political instability and post-election tensions, has affected the mainstream governance processes in the country. Without any form of contradictions, the current violent-conflict in the regions are having a toll on all variables for sustainable development including smooth governance activities. Just how devastating, might be the missing data. The ramifications on the nation's national budget in containing this scenario is in itself burdensome, as resources meant for productive ventures are transferred to high levels of militarization.

Even more disturbing is the cost of conflict on the state of resilience to the Cameroon state of affairs. The concept of resilience is critical to development and peacebuilding, as both are mutually reinforcing and are integral to governance. The quality of governance mechanisms inherent in any given country enables a comprehensive understanding why some countries cope well with sudden change while other countries suffer from it. By sudden changes, the author refers to shocks, including natural disasters, epidemics and political and economic changes, violence - like the ongoing anglophone crisis et al.

A country's level of resilience reflects how well it responds to sudden changes as highlighted. It is proven that, a country (for instance Cameroon) where civil resistance movements (English-speaking lawyers and teachers' movements) turns to be violent (the anglophone crisis) exposes the country's lack of adequate and effective restorative forces and as such are less resilient in the face of these civil movements. Such movements according to peace studies tend to be larger, more violent, and have aims that are more radical and continue for longer periods. This is a vivid description of the evolution of the current crisis in Cameroon, as lawyers and teachers movements became larger with followers at home and abroad, with heightened violence and with a more radical aim of secession, than, decentralization or regional autonomy. Without any doubt, this current crisis has demonstrated low levels of resilience in Cameroon.

Nonetheless, as earlier mentioned, the author focuses on governance-oriented solutions aimed at enhancing stability to withstand a shock or crisis, and maintain high levels of the social system, such as high levels of health, wealth as well as of peace and prosperity. For example, when a country has strong formal institutions, such as a well-functioning legal system, in combination with strong informal institutions, such as cohesive communities, it will theoretically respond or adapt to specific crisis more effectively. This is the objective of these governance proposals, as they will enhance coping capacities - the abilities for Cameroon to overcome the effects of the current armed crisis, while solving it; ensure adaptive capacities - to have leaders learn from past experiences of violence breakdown to enable appropriate adjustments for the future through the implementation of holistic peacebuilding interventions. These governance suggestions will further spur transformative capacities - as this would endow Cameroon government to build peace and conflict prevention institutions to foster individual and societal robustness and implant a peace culture.

\section{$>$ The consequence of poor governance is violence eruption}

It takes high degree of qualitative governance policies to understand the contradictions between conflicting parties, as these policies serve as a platform for growth and prosperity. These policies must as well ensure the effective usefulness of the contribution of informal alternatives to conflict resolution and transformation. An effective governing structure should ensure that conflicts, however inevitable, must not necessarily lead to organized violence, as these informal institutions will disenable conflicts from transforming into violence. This therefore means that, a good governance therapy on the reduction of violence must include a wide range of the informal sector in dispute resolution et al.

Conversely, why did the English-speaking lawyers and teachers' strike turned violent, in the case of Cameroon? Several other meso level peaceful protest, strikes and lockouts, civil disobedience, boycotts, as far as mass resignations have taken place elsewhere, yet, they did not erupt into violence. Another dimension of a source of violence, which ultimately go to test a country's resilience, is the advent of a discovery of a new mineral resource endowment, like the case of Nigeria's Delta region. Other countries such as Norway, Australia and Botswana are equally endowed naturally with mineral wealth and oil, yet none of these countries has experienced significant violent conflicts in generations past. Cameroon's petroleum deposit in the English-speaking regions have become a potential force underlying the reasons why the separatist request for independence of the southern part of Cameroon. In other countries, like in Botswana and Norway, it is a platform for stronger cohesion and national unity.

Away from the natural resources as a driver and force for violence, ethnicity and linguistic diversity has recorded violent conflicts across the world, like the case of Cameroon between the 'anglophones' and the Francophones on the basis of decried marginalization from the former against the latter's administrative structure. Interestingly, since the author's intention is based on the probability of scenarios turning violent, other societies wherein high levels of ethnicity, religiosity, and linguistic differences like in Singapore and Switzerland, have recorded the world's lowest levels of violence in history. This implies that, the commonality between Cameroon and Switzerland is their shared diversity in ethnicity and linguistics, however, their differences is that while the former's case (Cameroon) is erupting to violence, the latter's case (Switzerland) has never seen violence.

A further illustration is in the country Belgium. This country in 2017 experienced a dramatic crisis between parties representing its two main ethno-linguistic groups, including 541 days without a central government, but no violence erupted. The simple reason is that these countries have 
effective and equitable governance institutions with 'perfect' governing mechanisms aimed at discouraging violence as a means of resolving conflicts and disagreements. Therefore, governance is at the core whether a conflict turns violent. Contextually, whether the 'anglophone conflict' has turned violent is a matter of the quality of governance mechanisms in place to ensure productive and non-violent means of conflict resolutions, transformation and prevention. Impliedly, high levels of governance deficit in Cameroon is key to inciting conflicts (anglophone crisis) to becoming violent.

As earlier reiterated, this concept paper is concerned with violence as central to the problem of sustainable development; however, the control of violence, which is essential to the logic of Limited Access Order ${ }^{12}$, is not the focus of the author. This concept paper wishes to stress the failure of the classical economic framework of development to incorporate an appreciation of the dynamics of violence into long-term policy implementation. Whether or not, organize violence is a medium to resolve conflict is another argument altogether, as some authors like Tilly who observed that, leaders of organized groups as well as other related politically violent-leaders go to war when they believe the expected benefits of war outweigh its expected cost. These expectations goes as far as shaping the incentives of the subjects within violent groups, as youth join gangs and rebellions when the option is superior to the next best opportunity forgone.

\section{Why did the 'anglophone crisis' become this violent?}

Unequivocally, the author asserts that the failure of effective dispute-resolution-related governance strategies to regulate policies, which enhance the nonviolent means of resolving conflict, is at the core of the violent anglophone conflict. This assertion is merely at the level of the anglophone conflict becoming violent. Meanwhile at the level of the degree of the conflict's violence increasing in magnitude and intensity, the author attributes this failure in the lack of efficient informal conflict transformation institutions, as well as absence of peacebuilding investments in the national territory. When government fails to design policies to reshape the balance of power within its policy arena, violence is inevitable, reflective of the case of Cameroon. This means that, when the absence of core governance functions of commitment and collective action reach a certain threshold, the stage is set for violent demonstrations. All these governance failures are symptomatic of violent-friendly scenarios, as individuals and groups turn to use violence to resolve conflicts.

However, different political settings have different reasons for violent eruption. In Cameroon for example, the political setting lacks credible institutions to build the attitude of Cameroonians to shun violence as a means of resolving conflicts, thereby increasing the likelihood for a violent option. Intimidation institutions (e.g. abusive police unit) with threats of outrageous sanctions may decrease the cost of the violent option for only a short term. Intrinsically, irrespective of what combination of factors have caused the anglophone conflict to become violent, the failure of

\footnotetext{
12 North, Douglass C., john joseph Wallis, Steven B. Webb, and Barry R. Weingast. 2013. "In the shadow of Violence: Politics, Economics, and the Problems of Development". New York: Cambridge University Press.
}

governance is the product of such violent conflict. The question is this: how did the government fail?

\section{$>$ Government of Cameroon's Failures}

1. Failure to engage one of the significant peacebuilding variables - Dialogue: The GoC's failure to bring warring parties to an equitable round table bargaining setting has further enflamed the violence. This concept paper does not intend to uncover the history of the Englishspeaking Cameroonians, but to analyze solution-oriented narratives. Due to this failure, adverse effects is on the State's monopoly in the use of violence, as this dissatisfied group(s) - anglophones, map out plans to use violence to achieve their motives. With such bargaining failure, the GoC starts losing its grip on the positive use of violence. Ultimately, in such circumstances the military turn to misuse violence by preying upon English-speaking Cameroonians, rather than protecting them. ${ }^{13} \mathrm{~A}$ further effect on the state of Cameroon losing its monopoly in the use of violence is that, disgruntled citizens in these regions (North and Southwest) pick up arms for retaliation, as reflective in Cameroon. When a state's monopoly over the use of violence is being contested, as in Cameroon it is called governance without government or wartime governance. The effect of such cases is met with armed groups, and other informal local actors taking over and becoming the de facto authority, and sometimes undertaking functions normally performed by the state. Examples such as the Revolutionary Armed Forces of Columbia (FACR), the Liberation Tigers of Tamil Eelam (LTTE) in Sri Lanka, the Taliban in Afghanistan, the UNITA National Union for the Total Independence of Angola et al are all demonstrative of what AMBA Boys of Ambazonia Territory in Cameroon may become.

The GoC's failure in these governance processes is creating what is called ungoverned spaces, as the central authority is gradually losing its grip of authority in certain places in the English-speaking regions of Cameroon.

2. Failure to constraint the power of the state: Without any doubt, the state's monopoly over the appropriate use of violence is a precondition for security; however, it is by no means adequate to ensure the long-term security of the people and property. Just because the state has monopoly in the use of violence does connotes the assurance of people and property security. In fact, violent conflicts, even though minimal sometimes comes from the state itself, described as terrorism from above - defined as the abusive use of violence propagated by the state to suppress and oppress intent. Therefore, using the military and police arbitrarily on civilians is a driver for more violence, as is the case of Cameroon.

Most importantly, the misuse and abuse of state's power is mostly common in cases wherein the preferences of the political elites are constrained, thereby violence is the way to force political will. In the case of Cameroon, the author may not tell whether anglophone political elites have specific preferences or incentives why they may be resisting the change of political settings, as decried by the crisis' goals. Nonetheless, preferences of power-players and the constraints they face in implementing their particularistic

\footnotetext{
${ }^{13}$ Bates, Robert H. 2008. "When things Fall Apart: State

Failure in Late-Century Africa". Cambridge, .U.K.:

Cambridge University Press
} 
tendencies, always enable them to use violence to subdue adverse resistance. In other words, when elites in power adopt and implement policies that maximizes their gains, they will do everything (including violence) or use anything (violence) to get their wishes met, even at the expense of civilian lives. This is especially true when such elites are in perpetual fear of being replaced by different social groups or even by individuals within the same group. Simply for illustrative purposes, the anglophone struggle requesting secession may mean anglophone elites in the current government losing their positions and not gaining it in the event of a successful secession in the anglophone regions. So rather, than make any concessions with the anglophones, the English-speaking political elites downplay protest by violently engaging the military to suppress voices and block political change. To add to the anglophone example highlighted, in December 1989, the Ceausescu political regime in Romania attempted to resist political change by using the military violently. China was no exception when in June 1989, the communist party used military tanks to crush the pro-democracy movement rather than make any type of concession, as the world still remembers the military junta in Burma - present day Myanmar maintaining its power by using force to repress all opposition.

\section{Lack of Commitment:}

Without doubt, the onus for the reduction of violence or preventing further escalations in circumstances where violence already exit, lies at the heart of the decision and political will of the governing body - the GoC, in this case. This governing body or the GoC must create right incentives to discourage violence or the use of force in resolving grievances. It is a truism that, for states alongside powerplayers to commit and adhere to such commitments there can be some challenges, among which are real problems of coordination along cooperation lines. Considering that, the state is not an entity existing in a vacuum, as power-players who make up the socio-political and economic structure of the state, have wide-ranging falsity and disengagement attitude, which is a potential hindrance to resolving a conflict.

The spillover effect when policymakers are not committed to engaging pro-equity and social policies can be devastating, especially in a violent-affected scenario, as in Cameroon. In such cases, institutional distrust sets in, as citizens perceive the unwillingness of power-players and policymakers to keep to promise and pledges made in the past. Lack of institutional trust disregards political promises, generally perceived as incredible, as these combinations of factors leaves policymakers with thinner options available to handle crisis satisfactorily, such as the violent anglophone crisis or even as simple as the civil disobedience in the two conflict regions that comes with it. Lack of commitment is a crucial problem, which always generates inefficiencies in an entire political process, as an outcome ${ }^{14}$. Such scenarios are mostly common in situations where political power is de facto in the hands of the elites. These elites makes pledges because they have the power to, but fail to commit. Let us contrast this scenario with a situation in which political power was de jure in the hands of the citizens. All the citizens have to do, is vote the leaders away like in Nigeria. This therefore shows

${ }^{14}$ Besley, Timothy F., and Steven T. Coate. 1998. "Sources of Inefficiency in a Representative Democracy: A Dynamic Analysis," American Economic Review, 88, 139-56. that commitment problems arise when political power is not in the hands of the beneficiaries of the promised policies. Unfortunately, they are no third parties that can enforce the promises made by the state ${ }^{15}$. As earlier mentioned, trust in institutions stems from delivering on commitments, as it is related to desirable outcomes ${ }^{16}$.

It is therefore imperative that politicians and policymakers reshape their incentives to commit to gain trust of Cameroonians. Committing to resolve the anglophone crisis only is not what matters but consistent commitment is key to ensuring that violence reduces, and with little possibility and probability of the conflict relapsing. Commitment is a fundamental requirement to prevent further escalation of the anglophone crisis, reduce the possibility of conflicts becoming violent across the national territory, as such commitments will see the creation of conflict resolution and prevention institutions, as well as ensure engagement in holistic peacebuilding investments. That said, whether or not the $\mathrm{GoC}$ and the anglophones are able to reach an agreement to renounce and endow the state with the legitimate use of force is based on commitment. Commitment is vital in all fields of social interactions, even in economics. In economics, when governments fail to commit to regularization principles on foreign investments, it will scare away investors and slows down trade and the entire macroeconomic growth comes crashing. Take for example; the people's perception of the credibility of commitments can also augment their willingness to cooperate, tax compliance for example. Governments must therefore refrain from cheap talk and engage in binding walk to produce the necessary trust from the citizens' by delivering on commitments regularly.

\section{$>\quad$ Governance Strategies to reduce, prevent and} eventually solve the 'anglophone crisis'

As earlier reiterated, smart governance, can well reduce violence, and build attitudes to conform to nonviolent means of resolving conflicts if well executed. As highlighted commitment is core in determining, whether governance mechanisms aid in resolving conflicts.

\section{Solving the commitment problem:}

The solution of commitment is inherent in the mannerisms and wills of the political players. To solve the problem of lack of commitments, the in centives of the actors must change, as they should align their preferences with collective objectives of social and pro-equity policies. Incentives of these powerplayers should conform to the fundamental policies of conflict transformation and resolution in a wider context of peacebuilding and statebuilding. Whatever institutional arrangements to reduce violence, its success is tight to the credible commitments of policymakers, as they bind themselves in such a way that their promise become credible, even when it is in their short-term interest to break it.

The real question is this: just how possible can this be? It is however true that several other drivers are involved in a bid

\footnotetext{
15 North Douglass C. 1990. Institutions, Institutional Change, and Economic Performance; New York: Cambridge University Press.

${ }^{16}$ Olson, Mancur C. 1993. “Dictatorship, Democracy, and Development," American Political Science Review, 87, 56775.
} 
to fully understand why powerful actors would be credible or not, as one must examine a specific set of actors, rules and potential incentives to reach an agreement or even break it. An example of enforced credibility is granting independence to a central bank as a mechanism that governments will not use inflation to finance public investments.

Another example are anti-corruption agencies, as vital tools for constraining the use of public office for private gain. However, these institutions will be ineffective if they (institutions) are unable to alter the existing incentive structure in a way that makes it credible to enforce the new laws and the underlying contract of the new agency. The good news is that, around the world different institutions have been established to make commitment credible.

One-way to ensure commitment is using commitment devices or instruments, even though, the effectiveness of such commitment devices is where the power of the device to commit lies. For dispute resolution, the GoC can bring in a third party like the African Union to mediate on the dialogue process and ensure enforcement of commitment regulations to reduce violence and drop down arms. In fact, a complementary arrangement may be needed to provide a strong signal about commitment of policymakers.

An example of a solution to the commitment problem is the deployment of international peacekeepers who provided security guarantee for the agreements that ended the civil wars in Bosnia and Herzegovina, and Liberia and Sierra Leone. Third-party institutions of the sub-region of CEMAC can aid in the case of Cameroon.

\section{Creation of Alternative Conflict Transformation Institutions}

Institutions and commitments that harbors these committed policymakers are mutually reinforcing. When commitments are kept and respected, the 'simple game of mere promises' fade away and a real culture of incentive-compatible promises is implanted, as institutional trust grows. Institutional arrangements must provide right incentives to help ensure commitments become credible. By institutional arrangements, the author agrees with the World Bank's 2018 Report, which identifies four categories of governance institutions that directly shapes incentives for individuals, groups and governments to enable them to commit to not use violence to solve conflicts. They are sanctions and deterrence institutions, power-sharing institutions, redistributive institutions and conflict resolution institutions. Even though all these institutions are necessary for the context in question, that is Cameroon, since it is about an ongoing violent-conflict - the anglophone crisis, the author prefers to deal with the latter - Conflict Resolution Institutions.

Note that all the highlighted institutions deal with motives to reduce violence, like sanction and deterrence institutions for example, which is a main driver for the reduction of engaging the use of force by changing incentives and preferences. Sanctions and deterrence mechanisms can be a potential driver for maintaining security by increasing the cost of engaging in violence. The thin difference between the sanctions and deterrence and conflict resolution for example is at two levels in line with the objective of this concept paper; firstly, conflict resolution institutions are more probable in this context as the violence has already occurred, needless deterring armed civilians. Secondly, conflict resolution institutions have preventative peacebuilding as an integral part of their activities.

Other workable institutions like power sharing institutions through federalism and their role in the reduction of violence, can be a feasible tool but whether it will be successful in this context, - Cameroon, is entirely an argument to be heard. Power sharing will always resolve credible commitment problems among warring parties, as cooperation would be more likely. For more on this, kindly refer to the author's book entitled 'The Quest for Creative Governance: A shift from INSTITUTIONAL FORMS to INSTITUTIONAL FUNCTIONS. Lessons to improve the quality of Governance across the World".

Creation of Dispute Resolution Institutions in Cameroon is a requirement: The presence of dispute resolution institutions are very crucial for the reduction of violence and avoidance of conflicts to becoming violent. These institutional arrangements have the tendency to reduce violence, as disagreements can be solved productively without necessarily erupting into organized violence. The establishment of such institutions have a critical role to play as far as security, property rights, development, as well as reduction of violent conflicts are concerned. Dispute resolution can take different forms, ranging from informal to formal. The informal dispute resolution mechanisms are more prone to alternative dispute settlements. Such informal forms can be elder councils in villages; meanwhile the formal forms can be courts, ombudsmen or regulators as well as peace negotiations. The forms of dispute resolution mechanisms includes mediation, conciliation, and negotiation, where parties try to reach mutually satisfactory, self-enforcing agreements on their own. Another form of dispute resolution can be litigation and arbitration where disputant or conflictual parties mutually rely on a third party such as a judge or a jury serving as an arbiter, for the resolution and the credible commitment needed to enforce the resolution.

Dispute resolution institutions seek to resolve conflicts and violent conflicts over material resources, whether scarce or abundant, such as land, water, extractives, and movable assets. They also aim to resolve conflicts over violations of norms of socially acceptable behavior - usually codified into laws, including the use of violence and other types of defence. In addition, dispute resolution institutions facilitates agreements and preserve the peace, especially in circumstances where property rights are inaccurate. In states already plagued with weak institutions like Cameroon, strengthening these (formal) institutions can take decades, and so other forms of interventions should try to shape informal practices (Alternative Disputes Resolution mechanisms) and norms governing disputes. As earlier mentioned, the preponderant goal of dispute resolution institutions is to improve bargaining and commitment, and if well done, it will limit disputes and drastically reduce violence eruptions. Effective systems of dispute resolution mechanisms are essential to foster pacific bargaining process, commitment of conflictual parties as well as ensure order and hence, development. The effects of such workable dispute resolution systems, should promote investment, 
impersonal exchange and economic growth ${ }^{17}$. It should be mentioned that, the effectiveness of dispute resolution systems is linked strongly to the effectiveness and quality of a society's institutions, especially concerning the basic rules and regulations that structure social relations (Knight $1992^{18}$ and North $1990^{19}$ ).

\section{SECTION 3: GOVERNANCE STRATEGIES TO IMPROVE THE QUALITY OF GOVERNANCE AND PROPEL CAMEROON TO PEACE, PROSPERITY AND GROWTH}

When governments are transparent and accountable to the people, whom they govern, this leads to high levels of collaboration and increased cooperation between the government and its citizens, as this is crucial to important development indicators like internal revenue and tax collection. However, for this to be feasible, several governance huddles has to be eliminated with innovative problem-shooting governance methods. Below, the author proposes some of the governance solutions, as more elaboration are in his book captioned above.

Note that, for brevity purposes, the suggestions below will be explained narrowly, as a broader explanation of these solutions as well as other themes like Eradicating Corruption, Eradicating Illegal Financial Trends (IFT) and Enhancing Infrastructure Development, Decentralized Governance etc..., are in the author's governance manual - The Quest for Creative Governance.

\section{$>\quad$ Enhance Transparency and Accountability}

From previous experiences from different countries, it is widely illustrated that when leaders sets up appropriate, transparent and accountable management systems and implementable mechanisms, then effectively implement these tools properly and equitably, it will serve as key component of sustainable peace and development, as economic governance becomes achievable and feasible. In fact, government's legitimacy and trust in national institutions is linked closely to the transparent and accountable patterns in which governments commit themselves, as they provide public goods and services. Under such circumstances, economic activities will flourish and generate growth and prosperity. This will enhance the virtuous circle of prosperity, peace and development. This will ultimately improve peace and other measures of progress and will lead to less violence, as the society will be prone to non-violent means of conflict resolution and this will create a conducive atmosphere for business and growth. Such productive process will create stronger business environment, better functioning government and higher social cohesion. This will increase country's level in the Ease of Doing Business Index, and pull in foreign direct and domestic investments as well as encourage domestic trade ownership and transactions. This will ensure that society

17 Blattman, Christopher, Alexandra Hartman, and Robert A. Blair. 2014. "How to Promote Order and Property Rights under Weak Rule of Law? An Experiment in Changing Dispute Resolution Behaviour through Community Education." American Political Science Review 108 (1): 100-20

18 North, Douglass C. 1990. Institutions, Institutional Change, and Economic Performance. Cambridge:

Cambridge University Press.

${ }^{19}$ Knight, Jack. 1992. Institutions and Social Conflict. Cambridge: Cambridge University Press reaches higher levels of well-being, becoming more productive and wealthier. This will result in less expenditure on violence containment spending, releasing more resources to be free for investment in productive ventures.

This is what will happen when $\mathrm{GoC}$ becomes transparent and accountable, as they key into sustainable economic governance strategies for growth.

\section{$>\quad$ The quality of sound economic governance and financial expenditure management}

Sound financial management processes are crucial to economic governance quality, as it will improve the delivery of ultra-modern public service provisions. It will be premature to talk about sound economic governance without stating the dynamics governing financial expenditure management as it relates to the quality of economic governance. Several regulatory instruments mentions the important of rigid financial control, which emphasizes the core position Financial Expenditure Management occupies in enhancing good economic governance.

These instruments ranges from the NEPAD framework document, which notes that appropriate standards and targets, should be adopted to ensure macroeconomic stability. It prioritizes the need for African states to improve their management of public resources. It goes further to the $\mathrm{AU}$ as it asserts the need for transparency and accountability in the management of public's funds.

Similarly, IMF's codes stipulates that a national audit body, which is independent of the executive, should provide timely financial reports to the legislature and public about the financial state of government accounts. More so, the IMF's codes requires that "comprehensive budget laws" should govern all budget allocations and that there should be a clear legal and administrative framework governing the management of resources. Actually, both the AU and IMF commit African countries to transparent procurement and tendering processes.

These regulatory financial control instruments are reflective of the critical role financial expenditure occupies in fostering sound economic governance quality. These regulator instruments stresses on: effective economic governance on expenditure or public investment, effective systems to control and prosecute wasteful expenditure, efficient measures for sound basic accounting controls, adequate systems to monitor transferred and transfers of funds, improvements in human resource management, cost effective procurement, audited financial statements in line with existing financial laws and regulations, and asset managements. It will be important to refer to the author's book mentioned above for some of these determinant mechanisms through which, sound economic governance can be feasible, if applicable.

\section{> Provision of Qualitative Public Service Delivery}

At the core of credible governance and public administration is an effective public service delivery, whether understood in whatever context is immaterial to this study. Anything short of this provision, that state is a failed state. Therefore, a capable public service, based on whatever incentive-based system, has a better bearing to enhance good governance, as these services will rebuild national cohesion and the relevance, credibility and trust in government will augment. 
As a central actor in the whole governance process, the public sector is called upon to be an agent of change and to ensure that it undergoes self-transformation to adapt and manage the changed and the overall social governance terrain.

For example, the case of Rwanda is astonishing to recall. The experience of Rwanda illustrated that building institutions, which seeks to enhance the provision of substantial public services is essential to ensuring the commitments of good governance and the achievements of economic and social goals of the state. Take another lucid example; South Africa's experience also indicates that it is not possible to transform a government and therefore a State without utter transformation of the public service. The public service sector therefore needs to be revamped, coherent, productive, transparent, accountable, collaborative, representative and committed to respond to the needs of the citizenry and to attain peace and development. Let us look at a program for growth by another African country, this time from North Africa - Morocco. The Morocco 2040 growth program ${ }^{20}$ targets a wide spectrum of reforms, from macroeconomic policy to labour markets, and to the social sector. However, underpinning these reforms is the need for transformation of the public service institutions and governance in the light of quality public service provisions. Predominantly, the public sector enforces the rule of law, redistributes income, regulates economic activity, and provides essential social services, including health and education - which is analysed in the author's book aforementioned. Failure in this dimension of the Morocco 2040 growth program would put all other sector programs at risk. This outlines such importance the public service provision holds in the Moroccan development agenda, just like any other emerging country.

Creating an ultra-modern public sector is no small task however, because it requires a commitment to building a public service based on merit rather than political affiliation. The proposed setup for public sector reconstruction varies with different countries, but in the Morocco 2040 scenario, reforms started with human resource management in the public service, aimed at merit-based hiring, promotion, and dealing with absenteeism. In the case of Morocco 2040 growth program, reforms to redesign the public sector came from two key management functions, which are however, also critical for success as further explained in the author's governance book.

Transforming the public service as earlier mentioned needs a radical change. It cannot be met hurdles-free, that is not possible as some in-depth public service transformation examples are explained in the author's book.

Other themes that portray learnable lessons to be emulated by the GoC are the, Enhance commitment and cooperation; stimulation of the Governance environment through the creation of effective, accountable and equitable institutions, as these matters for Growth; Diverse strategies to development; Improving governance through assorted channels; are few relevant topics in the author's book on Governance for further references.

${ }^{20}$ Glenn-Marie Lange, Quentin Wodon, Kevin Carey as Editors. 'The Changing Wealth of Nations 2018. Building a Sustainable Future'. World Bank Group

\section{CONCLUSION}

Governance is at the core of effective implementation of social policies; however, it is needful to understand what drives the concept of governance to enable researchers and policymakers innovate along the lines of governing principles. It is the author's wish that this concept paper will meet contemporary governance deficiencies, as it spreads beyond the borders of Cameroon and stretches to the world. Contrary to ubiquitous thinking, the core processes of governance is not limited to the responsibility of the state solely. Without controversy, formal political institutions are at the forefront in championing and regulating the effectiveness of equitable social policy implementation. Nonetheless, all other sectors have their role to play, as the usefulness of this concept paper is not limited to government officials only.

Most important is the need to upgrade the common economic governance strategies, which is a common requirement in several sub-Saharan African countries. This cannot be fully done without exploiting the trends through which economic governance is affected, including all forms of illegal financial trends, with special emphasis on the canker - corruption. A complete revamp of such governance plagues will require a re-modelling of certain governance principles like Transparency and Accountability through citizens' participation. The classical but outdated style of accountability through year-in government reporting has demonstrated its ineffectiveness, as policies and persons are at risk of capture by the powers that control the policy arena. Therefore, involving citizens is a governance modification therapy the book is suggesting with articulated roles and duties vis-a-vis states. As expounded in his book, the author hopes that an improvement in economic governance quality will enhance qualitative public service delivery, as it will ultimately spur growth

However, the upshot for the effective and efficient implementation of these governance mechanisms highlighted above, will witness the smart creation of a conducive governing space in a bid to re-stimulate the entire governance environment through the establishment of effective and equitable institutions. Nonetheless, excessive reliance on the forms institutions take, rather than the functions they are intended to undertake will yield no results, as the actual commitment of politicians, policymakers and other governance-stakeholders to use local measures of legitimacy, representation, accountability and transparency for development, unlike clientelism, is of utmost importance. This implies that the quality of governance may not yield dividends without appropriate behavioural engagements of leaders, regardless of the institutional structure. It is therefore, imperative that policymakers reshape their incentives to properly implement and manage governance systems - being the machinery through which better outputs are realized.

The author clearly advocate for a governance strategy with central objective to promote a participatory partnership with the civil society, private sector and all other development actors. At the backdrop of such heterogeneous/citizens' engagement in the whole decisionmaking processes, governance institutions need to make use of effective strategies including management systems and tools that must enhance transparency, effectiveness, 
dialogue, participation and accountability, access to reliable information and communication technology et al.

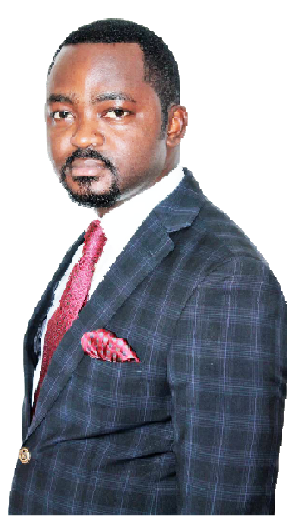

Maxwell N. ACHU is a Cameroonian Diplomat, Author, Civil Society Activist, Conflict Transformation Researcher and Expert in Positive Peacebuilding across the African continent, and beyond. He has as vision to inspire and embolden youth's involvement in nation- and statebuilding activities within the context of societal reconstruction through massive peace learning. This article is a partial reflection on a holistic and rigorous research conducted by Maxwell N. A. on "Positive Peace for Africa", a peacebuilding project with objectives to implant a peace culture through education on the variables of Sustainable Development Goals and Governance Strategies. In addition to other analogous research work carried out by the author are:

$>$ The Quest for Creative Governance: A Shift from INSTITUTIONAL FORMS to INSTITUTIONAL FUNCTIONS. Lessons to improve the quality of Governance across the world.

The Role of Religious bodies in Peacebuilding,

$>$ The Role of the Media in Positive Peace Reconstruction,

$>$ The State of Peace in Ghana,

$>$ The Proposal Paper on the Short- and Long-Term Peace Strategies for Cameroon,

The Conclusions on the Anglophone Crisis Risk Assessments, and the Predictability of the Crisis' Intensity. The clock is ticking...

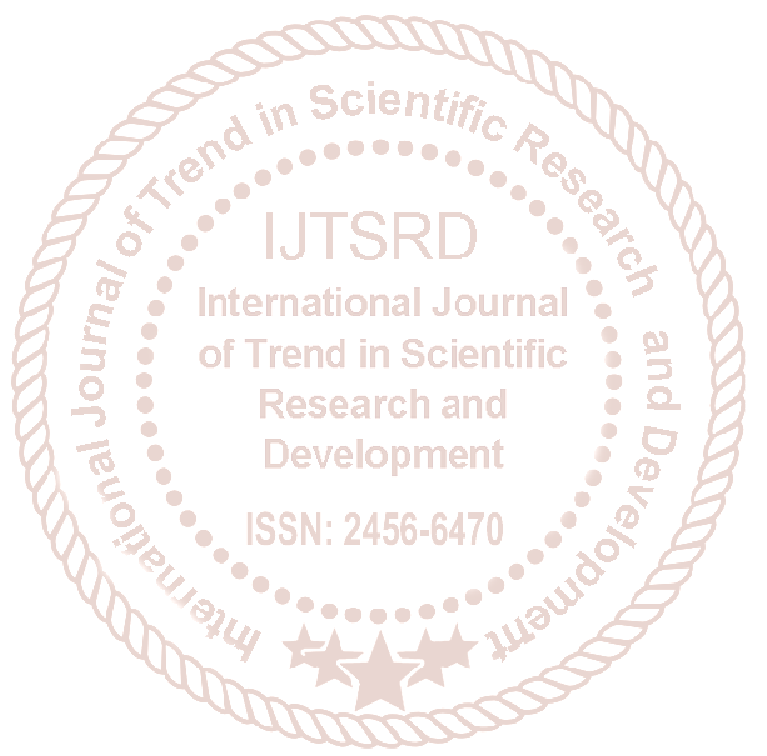

